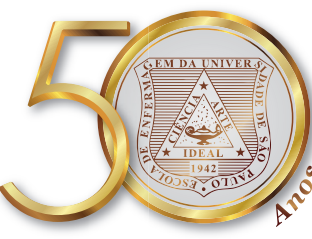

\title{
Perceptions of critical and emergency department nurses regarding changes in their professional role
}

\author{
Percepção dos enfermeiros dos serviços críticos e de emergência em relação a mudanças no \\ seu papel profissional \\ Percepciones de enfermeros en el departamento crítico y de emergencia en lo que se refiere a \\ cambios en su papel profesional
}

Maria NK Karanikola', Margarita Giannakopoulou², Meropi Mpouzika1', Christiana Nicolaou', George Tsiaousis ${ }^{1}$, Foteini Vouzavali $^{3}$, Anna Koutroubas ${ }^{1}$, Elizabeth DE. Papathanassoglou ${ }^{4}$

How to cite this article:

Karanikola MNK, Giannakopoulou M, Mpouzika M, Nicolaou C, Tsiaousis G, Vouzavali F, et al. Perceptions of critical and emergency department nurses regarding changes in their professional role. Rev Esc Enferm USP. 2017;51:e03287. DOI: http://dx.doi.org/10.1590/S1980-220X2017014403287

${ }^{1}$ Cyprus University of Technology, School of Health Sciences,

Nursing Department, Limassol, Cyprus.

${ }^{2}$ National and Kapodistrian University of Athens,

Department of Nursing, Athens, Greece.

${ }^{3}$ Technological Educational Institute of Athens, Nursing Department, Athens, Greece.

${ }^{4}$ University of Alberta,

Faculty of Nursing, Edmonton, Canada.

\begin{abstract}
Objective: Preliminary investigation of the way Greek critical and emergency department nurses conceptualize changes in their professional role. Method: A qualitative focus-group methodology was applied. Following purposeful sampling and informed consent of participants. Results: Participated eight individuals. The need for enhancement of nurses' participation in decision-making in order for an actual change in their professional role to be achieved was the central theme of participants' narratives. Perceived advancements in professional role performance regarded: evidence-based practice; technology; education, knowledge; clinical skills; research; heightened nurse-physician collaboration. Perceived reasons why these advancements failed to enhance nurses' professional role were lack of meritocracy; competitive relationships; lack of support among nurses; insufficient managerial support; budget limitations. Conclusion: Despite advancements in clinical practice, participants did not deem that their professional role was enhanced significantly, as participation in decision-making and control over practice remain limited.Interventions targeted to enhance nurses' participation in clinical decision-making, and overall professional autonomy are recommended.
\end{abstract}

DESCRIPTORS

Professional Autonomy; Decision Making; Emergency Nursing; Critical Care Nursing; Professional Role. 


\section{INTRODUCTION}

Nurses' professional identity and role performance are developed through education and within the clinical practice environment ${ }^{(1)}$. Nurses employed in Emergency Departments and Critical Care settings (ECCNs) are moving towards a new professional era encompassing a highly sophisticated clinical environment, education in advanced practice and augmented clinical duties denoting that new professional roles may need to be developed ${ }^{(2)}$. This role transformation is inevitably followed by changes in professional identity and attitudes ${ }^{(1)}$. Moreover, extensive data show that nursing professional identity and role performance issues, such as values, beliefs, motives, experiences and attitudes are associated with the ability to meet safety and quality-related standards with regard to the provided healthcare services ${ }^{(3)}$. Thus, addressing changes in ECCNs' perceptions of their professional identity and role performance may be of high importance for patients' outcomes and nurses' organizational and psychological empowerment ${ }^{(4)}$. Illustrating the way ECCNs perceive changes in their professional role and related factors may bring forth both positive and adverse aspects of change, thus providing insight for targeted interventions to support positive transformation.

During the last decades, many ECCNs have been enjoying progressively increased professional status and clinical autonomy, more opportunities for inter-professional collaboration and support from administrative policies ${ }^{(2)}$. However, Greek ECCNs perceive their professional status and the quality of collaboration with physicians as low, despite their academic preparation ${ }^{(1)}$. Thus, it is interesting to explore whether Greek ECCNs perceive any changes in their role performance following international progress in the field ${ }^{(3)}$. Additionally, current conditions in the Greek healthcare system due to financial crisis impose elevated levels of vocational distress on ECCNs due to increased job demands, workload and restraints on employee rights, such as days off and educational leaves ${ }^{(5)}$. These conditions imply an adverse impact on nurses' professional issues, as well as their ability to meet patient safety standards ${ }^{(4)}$. Annual admissions in Intensive Care Units (ICUs) were increased in the last five years, while, the number of employed nurses in both emergency (EDs) and critical care settings was decreased ${ }^{(6)}$. Thus, most of the Greek EDs operate with one third of the lowest safe staffing rate according to the recommendations of the National Nurses Union $^{(7)}$. Additionally, an $11 \%$ rise in admissions' rate was noted in EDs, a percentage much higher compared to the general admissions' rise in public hospitals, namely $8 \%$, for the same period ${ }^{(7)}$. These conditions imply an adverse impact on the professional attitudes of employees, as well as their psychological adjustment ${ }^{(8)}$. Additionally, the augmented nursing workload due to the increased morbidity in the general population has to be taken into account ${ }^{(5)}$. Furthermore, the continuing lack of advanced practice roles in Emergency and Critical Care Nursing in Greece, hinders nurses' ability to meet the increasingly complex needs of acutely ill patients ${ }^{(4)}$. However, limited data exist regarding the way ECCNs experience changes in their professional role associated with the current conditions in European healthcare systems in terms of budgetary restrictions, insufficient workforce and the rising needs of health services consumers ${ }^{(9)}$. The objective of the current preliminary investigation was to qualitatively explore the following research question: "What is the lived experience of ECCNs in Greece regarding changes in their professional role?". Special focus was given in Greek ECCNs' perceptions and feelings about: a) the types of changes in their professional role since ones' entry to the profession, and b) the factors contributing to these changes.

\section{METHOD}

\section{DESIGN}

A focus group approach informed by the phenomenological method was used ${ }^{(10-11)}$. Although content analysis is commonly used for focus group interviews analysis, we chose to go one step further and employ phenomenological methodology to explore not only various aspects of participants' experience but also the central theme of their experience and how various themes tie together ${ }^{(11)}$.

\section{ETHICAL CONSIDERATIONS}

The current pilot study took place as a preliminary part of a wider project exploring how changes in healthcare milieu affect the professional attitudes of nurses and their mental well-being, approved by the Cyprus National Committee of Bioethics (NF: CNCB EP 2010.01.12). The voluntary nature of participation, assurance of confidentiality and anonymity were clearly described in a form signed by the participants prior to the study. Aiming to assure anonymity, the researchers reffered to the participants by the letter "P"(Participant), followed by numbers, according to the sequence in which the participants responded to the questions.

\section{SAMPLING AND SETTING}

A purposive sampling of delegates attending an annual, three-day conference held in Athens, Greece in emergency and critical care in 2013 was applied. The focus group took place in a separate room of the congress centre. During registration, all delegates had the opportunity to be informed of the purpose of the study and declare their willingness to participate. Literature indicates 6-10 persons to be included in a focus group ${ }^{(12)}$, thus 8 people out of the 20 who stated their willingness to participate were selected according to inclusion criteria (vocational experience in the clinical area of EDs or ICUs of minimum 2 years; administrative nurse or staff nurse), following a personal communication via telephone with the researchers (MK). Special attention was given in order to avoid that the final participants were familiar with each other or the coordinator of the focus group (MK). The mean age of the participants was 38 years (minimum $=30$, maximun $=50$ ) and their mean work experience in EDs and ICUs was 7,5 years (minimum=2, maximum $=16$ ). Two of them were male. One of the particioants was vice and one head nurse. Two of the participants were $\mathrm{PhD}$ holders and three of them were Master's degree holders. 
Nevertheless, sampling for concept elicitation interviews, i.e. conceptualization of professional role changes, should be not only purposive, but adequately diverse to sufficiently represent the experiences of the target population ${ }^{(10-13)}$.

\section{Data collection}

Data collection was achieved in the course of one focus group since the present study was a pilot one. Although focus groups add complexity to the phenomenological approach due to multiple voices and the interactive environment, they can also allow for the exploration of the "collective" along with "individual" lived experiences ${ }^{(11)}$. Therefore, focus group was the most appropriate for the current data collection, since perception of professional identity is shaped both at individual and collective level. Additionally, the different backgroung characteristics of the participants, in terms of age or clinical experience, allows multiple perceptions and feelings coming from different persons to be addressed at the same time. This, not only adds plurality to the collected data, but is also time consuming and most importantly may further prompt the expression of ones' feelings and perceptions when knowing that other people have similar experiences. Moreover, phenomenological focus groups are useful for clarification and cross-checking of interpretations among participants, as well as between participants and researcher ${ }^{(12-13)}$. The focus group interview guide included broad questions centered on the living experience of changes in the professional role of nurses employed in ICUs and EDs. The appropriateness of each question was assessed by a group of experts comprised six academics experienced in the qualitative research. Following their feedback some questions were removed and the language was simplified. The focus-group interview lasted two hours and $10 \mathrm{~min}$. The following questions were included: Please describe any changes you perceive in the nursing professional role or in the healthcare system regarding nursing since you entered to the profession and How do you feel about these changes?

\section{ANALYSIS OF THE DATA}

Data analysis performed independently by three researchers (MK, PE, MM), who highlighted, interpreted and organized the quotes that captured participants' perceptions and feelings according to two distinct groups of topics: a) changes in professional role and b) factors contributing to any changes. Next, the investigators identified common themes regarding the two aforementioned groups of topics, which were further discussed until main themes and subthemes under these two categories of topics emerged. Furthermore, the researchers identified the way these main themes and subthemes were associated, a procedure that unveiled the central theme of the phenomenon under research.

The triangulation of data analysis with three researchers, along with the implementation of nine criteria of research rigour assured the integrity of the analysis ${ }^{(10)}$. These criteria are: a) resonance (the analysis of the phenomenon by the researchers has an impact on those who read it), b) reasonableness (study findings comprise a logical interpretation of the analyzed phenomenon),c) representativeness (an in depth interpretation of the phenomenon has been achieved), d) recognisability, (individuals from the study population identify parts of their own experience with the phenomenon in the interpretation given by the researchers), e) raised consciousness, (expansion of one's awareness in relation to the phenomenon), f) readability (high quality of the written interpretation of the phenomenon), g) relevance (applicability of the results in Nursing, h) revelation (illumination of unknown aspects of the phenomenon), and i) responsibility (ethical and deontological obligations to participants). The researchers reached back to participants in order to present and verify the findings. Only five out of the eight participants participated in the verification phase due to heavy workload, validating the interpretations of their narratives, thus confirming the criteria of reasonableness, representativeness, recognisability and readability. Moreover, participants confirmed that during the presentation of the findings they came across aspects of the phenomenon that they had not considered before (revelation, raised consciousness). Finally, they discussed the significance of the study results in terms of their applicability in Nursing (relevance, resonance).

\section{RESULTS}

The central theme that emerged was the need for enhancement of nurses' participation in clinical decisionmaking and policy development, in order for an actual change in nurses' professional role to be achieved.

A participant (P8) said: (...) (the nurse) has not been able to participate effectively or actively enough in decision-making at any level, the hospital administration level or the level of health policy-making. As I see it, if this doesn't happen, I think it'll be too difficult to see any change in the nursing role.

Participants were specific about the constituents of desired change, which included increased participation in clinical, unit operation and policy decision-making, all resulting in enhancement of both control over nursing practice and professional autonomy.

The schematic presentation of the association among the central theme and the main themes illuminated by the participants' narratives is presented in Figure 1.

\section{Main themes}

\section{Conceptualization of the Changes in the PROFESSIONAL ROLE OF NURSES: TWO DIFFERENT GROUPS OF INNOVATIONS}

The participants, in the process of describing recent changes in the nursing professional role, made a clear distinction between changes in the wider nursing role context and changes in the bedside clinical practice. The former group pf changes was seen as related to professional issues of Nursing (broader professional role aspect), while the latter was seen as related to everyday clinical practice (bedside professional role aspect).

(P5): As for the changes (...) I want to talk about the (different) roles, because I think there is some confusion there (...). There is the big picture (...) and then there are the specific things we do in everyday clinical practice (...). 
The changes in the broader aspect of the professional nursing role were perceived to involve alterations in issues related to the professional orientation of nurses, such as professional status, degree of autonomy, education, quality of collaboration with physicians and peers and advanced roles. Thus, the focal point of this group of changesaspect were nurses themselves, since the main effect of relevant changes seemed to directly and positively influence the vocational well-being of nurses.

(P1): (The nurse) nowadays has increased status. There is a disease-control nurse now, for instance (...). (A nurse) is able to argue about these (clinical) issues (...). The relationship with physicians has changed.

The following quotes illuminate the importance of increased accountability, professional status enhancement and heightened nurse-physician collaboration during the last two decades:

(P1): many things have changed. Doctors listen to nurses now, because they depend on us on so many things. That's a big change.

(P3):Nowadays, in the hospital setting, these small new roles have given nurses enormous professional status (...).

Moreover, participants deemed that participation in post-graduate Master's and Doctoral programs resulted in the establishment of novel, advanced roles, and subsequently in implementation of critical thinking and evidencebased practice:

(P5): What has changed is that the nurse does not accept unquestionably or without assessment the clinical decisions of the therapeutic team any more. And this has come as a result of education, meaning post-graduate education, Master's degrees, doctoral degrees, research (...).

The changes in the bedside professional role wer seen to encompass: i) actions that directly benefit patients, ii) implementation of the nursing process, as the method of nursing work, and iii) nursing tasks as they are integrated with those of the inter-professional health care team.

(P5): The key elements of the nursing role are cure, care, alleviation (...). As far as these are concerned, the role of the nurse has not changed. What is happening lately is that clinical practice has improved, but no change of role there (in the objectives). My role has remained the same, the nursing role remains the same (...), because the focus is still on care, our role is still about care (...).

Thus, the focus of this group of changes regarded the benefit of patients and achievement of optimal clinical outcome. Specifically, the main body of these changes seemed to incorporate advancements in the way everyday bedside clinical practice was implemented. However, participants contentedly maintained that the core of their bedside professional role, as it is reflected in the objectives of everyday clinical practice, remained unchanged, since it was still person-centered and,focused on care, cure and alleviation of suffering. Although the need to empower paients appeared to be part of the participants' focus, they did not talk abourt enganging them in clinical decisions, as an achieved or even desired change.
Overall, perceived advancements in the bedside professional role seemed to be associated with evidence-based practice and nursing research; increased knowledge base and competence in clinical skills; effective nurse-physician collaboration; use of innovative technology and education in advanced clinical roles. In particular, participants highlighted the importance of changes in clinical assessment and critical thinking prior to implementation of interventions in emergency and critical care. These, along with participation, albeit limited, in clinical decision-making, were regarded as accounting for improved clinical outcomes and enhancement of the bedside professional role in recent years:

(P3):(...) All these (clinical practice components) have changed, and they have been changed by nurses through research (...), by the pioneers. (...) When I daredback in those years, 25-26 years ago, to say 'do not do this... there is wound infection right there', the surgeons started shouting at me, and intimidating me, and all those sorts of things (...).

Another quota which highlights augmented knowledge and competence in clinical skills compared to the past is the following:

(P5)(...) I'll do what I've got to do [with my ICU patients]; but now with a whole different set of skills than 10 years ago (...).

The use of innovative technology in provided emergency care following nurses' initiatives is described bellow:

(P3): the administration sent us abroad to get training in triage; we brought back the programme they had there, fully electronic, and we used it in our Emergency Department. We were the ones to propose all that (..).

\section{OBstacles AND FACTORS ENHANCING PROFESSIONAL ROLE CHANGES}

Furthermore, participants described: i) the way role changes have to be implemented in order to be accepted from peers and the factors which promote these changes, and ii) obstacles to these changes. Firstly, participants gave emphasis to personal effort, organizational culture and quality of interaction among peers, in order for a change to be achieved. They described how personal initiative, engagement and evidence-based knowledge, in combination with communication skills and positive influence may support achievement of the desired changes. Participants deemed that respecting the particular unit culture and related informal norms was crucial for effective implementation of advancements related to everyday bedside practice. They seemed to emphasize behaviors and values commensurate with transformational leadership, as in the quote below:

(P5):(...) what matters most is your behavior and not the data or information you can provide (to your peers) (...). So I went next to them [my colleagues] and performed all the procedures they were performing, but sticking to the guidelines [instead of explaining how it's done]. As a result, they realized, just by watching me, that they could actually use proper scales and make effective assessments; and see a positive clinical outcome out of that (...) That's the duty of the nurse who wants to contribute to change (of the clinical practice). 
The descriptions of the participants about the magnitude of clinical leadership for the achievement of professional role changes revealed that they conceptualized themselves as leaders in terms of someone who influences and inspires others, rather than a manager with authoritative power. Overall, it seemed that being the agents and protagonists of professional role change was important for these nurses.

Additionally, in order for a change in professional role to be achieved, participants set the following prerequisites: i) an effective administrative policy in terms of organizational empowerment, and ii) the enhancement of the culture of professionalism. Under this scope, the objective of administrative policy was the successful allocation of resources and managerial support of new roles and innovative initiatives. Thus, participants did not seem to regard management per se as accountable for change and innovation; rather they regarded change as initiatives arose at the unit level, and particularly from staff nurses.

(P3):(...) when someone who has the knowledge joins a team, he or she ruins their (peers') peace and quiet. People are reluctant to changes. The basic thing is how to get innovative approaches accepted. I feel lucky because I am able to push forward novel tactics because of my administrative position (...) Everything goes, especially when you have the support from administrators who ask from nurses to take up new roles (...). That's really it. Professionalism in Nursing.

Furthermore, knowledge and continuing education, along with leaders in the clinical area, were described as central factors that can lead to advanced clinical roles. Nevertheless, the importance of those individuals within the nursing team who would be the frontrunners in adopting and implementing all novel advances was highlighted by the participants.

(P3): I believe that knowledge is one of the things that promote innovative changes (...). If we have, say, 5 nurses out of 20, who are industrius, educated up-to-date and able to positively influence and educate the rest of us s, then our clinical practice will be so much better, and our job more advanced (...) If you tell them [fellow nurses] do it this way, because that's how it is supposed to be done, they will do it only for as long as you're there. If, however, you tell them do it like that because this will benefit the patient, I think that'll be different. They will stick to it (...).

The participants, also, deemed patient safety as a major motive towards the implementation of new approaches, which would further bring on innovative changes in the professional role and at the bedside. They, additionaly, provided reasons for which desired advancements in the nursing profession have, so far, failed to enhance their roles. These obstacles included: lack of meritocracy; competitive relationships and lack of support among nurses; dysfunctional organizational culture and informal norms; insufficient managerial support and ineffective administrative policies; heavy workload, coupled with nursing shortage and budget limitations; and finally, lack of evidence-base in everyday practice.
(P1)(...) I decided that I could change some things (...) for sure, there are nurses who are exhausted. Staff shortage wears me out the most (...) however, new roles need to be implemented (...).

(P7): (...) nursing managers, often in line with hospital administrators, do not support our continuing education, because they say that we have no prospect for improvement.

Apart from non-supportive administrative policies, participants mentioned lack of support from their peers and the competitive environment, along with lack of meritocracy as major impediments to the evolution of the nursing profession. Disappointment and loss of hope were described as the main feelings raised from such circumstances.

(P7): (...) and there is always the same old thing all over Greece, lack of meritocracy and political favors. Those things are so strong, and I hope all this will change within the nursing profession, but I'm afraid there will always be nurses hostile to anyone trying to do something good (...). If we keep on with that attitude in Greece, there'll be no step forward (...) this is very difficult and disappointing (...).

The conflict between young nurses entering the profession and older experienced nurses was also noted, suggesting a tension between new and traditional nursing roles, since participants appeared to perceive themselves as agents of change, rather than anticipating change to be brought on by external influences.

(P5): (...) a really nasty environment (...); ironic comments all around by old nurses (...) difficult (...).

This lack of support for the initiatives taken by participants was experienced mainly through gossiping and labeling towards them, both resulting in a climate of hostility and marginalization.

(P8): (...) I believe that there is hostility; people who try to bring about changes are targeted (...). It's frustrating to live in such a hostile work environment (...) Those two-faced people, all this gossiping. It gets to you at the end of the day (...).

(P6): (...) There is no real support in our field. From the smallest to the biggest change [you try to bring about]. People are not at all supportive; they're two-faced. In front of you they say you are good at it (bringing new things to the field), I'm happy for you, but their body language says otherwise (...).

Nevertheless, participants described adverse feelings associated with lack of support, labeling and poor relationships with their peers, which further seemed to negatively affect their well-being. Sadness and depressive mood were described as consequences of this type of rejection by colleagues.

Nevertheless, the recent financial crisis that has afflicted Greece was perceived as another barrier to the implementation of new advanced roles.

(P3): I set high goals in my work. The problem is I realize that the means I have to meet them are insufficient. I don't know if we are able to succeed in what we do, mainly because of the economic situation and the lack of hope [due to the crisis). 


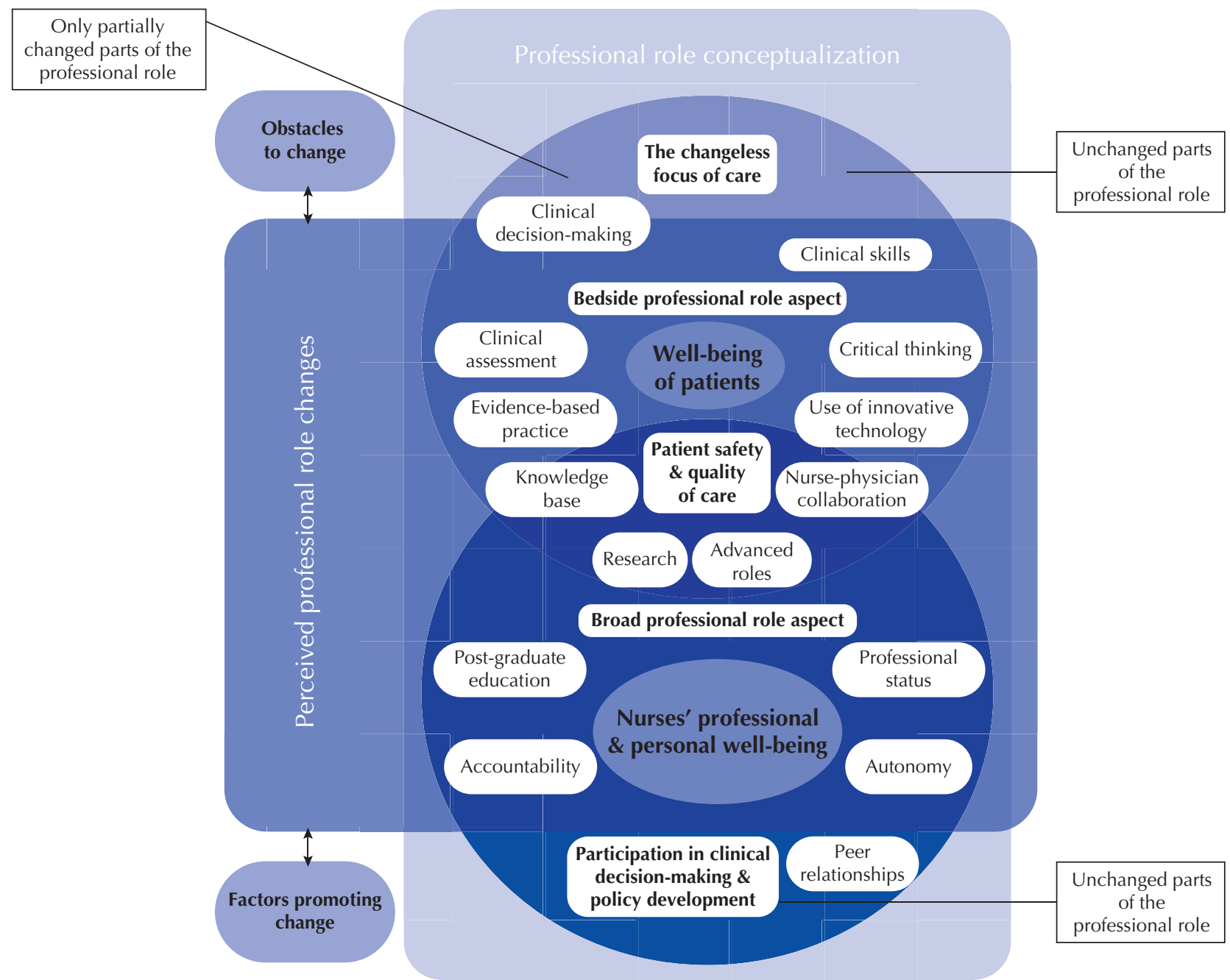

Figure 1 - Schematic presentation of the association among the central theme and the main themes illuminated by the participants' narratives - Limassol, Cyprus, 2017.

\section{DISCUSSION}

The most important current finding was that the Greek ECCNs still have limited participation in clinical decision-making and policy development which was highlighted as the principle factor that hinders an actual change in nurses' professional role. This finding is in line with other researchers $^{(14)}$ who reported that ICU nurses are not allowed to perform many procedures due to organizational boundaries; however due to circumstances, such as physicians' shortage, in some cases they are urged to engage in interventions and clinical decision-making they are formally not unauthorized to, implying that there is space for relevant improvements in critical care nurses' autonomy. There is anecdotal data that this may also be partially happening in Greece, explaining to some extent the findings of the present study. In contrast, in UK acute care hospitals, NHS reformation has resulted in increased organizational and educational empowerment in order to support nurses' authority in clinical decision-making, especially for those employed in EDs and ICUs, as the standards of patient safety necessitate ${ }^{(15)}$. Therefore, in order for a meaningful change in nurses' role to favorably affect both patients' outcomes in terms of safety and quality of care and ECCNs' professional orientation, enhancement of nurses' participation in clinical decision-making and health policy development is needed.

Specific interventions towards this aim are necessary, including transformations in healthcare policy and advancements in Greek ECCNs'education and empowerment. The importance of such interventions is highlighted by data showing that participation in clinical decision-making and policy development is directly linked with professional autonomy ${ }^{(16)}$, while nurses' professional autonomy is associated with safety and quality-related standards of the provided healthcare services ${ }^{(4)}$. Additionally, heighten autonomy and increased participation in decision-making have been associated with ECCNs' professional and personal well- being ${ }^{(2)}$, which are also related to patient safety ${ }^{(4)}$.

Although in Greece various Master's and specialization programs have existed for at least two decades, advancement of nursing practice and inclusion of nurses in decision-making have been slow ${ }^{(17)}$. This is commensurate with participants' views that knowledge alone does not suffice for change and that proper support is necessary. Advanced 
practice positions, which encompass the roles of educator, leader and researcher, have been associated with empowered participation of nurses in clinical and policy development decision-making ${ }^{(18)}$. Advanced practice programs, are well established across North America, Europe and Australia ${ }^{(18)}$. However in Greece, there is still a lack of advanced nursing roles. Therefore, establishing post-graduate education in advanced nursing practice is advisable.

Furthermore, in the Greek healthcare system, power imbalances among healthcare personnel are common ${ }^{(19)}$. Thus, implementing the principles of inter-professional collaboration and challenging traditional hierarchical relationships and conventional nurse-physician stereotypes will be necessary for enhancing nurses' participation in clinical decision-making and policy development ${ }^{(19)}$. These issues were addressed by participants who maintained that nurses need to be able to "make the call" if improvements in patients' outcomes are to be attained. This has to be achieved not only at the unit and hospital levels, but also in healthcare policy. In Greece, nurses have only recently been included as members in the Central Health Council, called "KESY", as the central advisory committee of the Greek Ministry of Health concerning health sector issues. However, they still have to develop the political alliances and skills that will allow them to effectively participate in the transformation of healthcare systems.

Despite the need for advanced nursing clinical practice, a number of challenges for its successful completion within the Greek healthcare settings still exist ${ }^{(20)}$. These include not only difficulties due to the current financial crisis, but also organizational culture and stereotypical norms prevailing in Greek emergency and critical care settings ${ }^{(19)}$. Participants, herein, used emotionally-charged descriptions in order to disclose their adverse experiences and feelings of frustration and distress regarding initiative taking and efforts to evolve everyday bedside clinical practice. Tension between new and traditional nursing roles has been addressed before in the literature ${ }^{(21)}$. However, international literature also shows that the attitudes of nurses towards profession- related changes, and mainly regarding expansion of their authority, are influenced by the degree of professional autonomy held and work relations, whilst novice nurses are more likely to be optimistic concerning vocational-related transformations ${ }^{(22)}$.
According to the $\mathrm{ICN}^{(23)}$, nurses are agents of change and every decision made by them within teir practice may have a important input into the overall success of the healthcare system. These data support the necessity of interventions aimed at improving the quality of relations among ECCNs, as well as increasing their accountability and subsequent clinical autonomy in order for an effective role change in terms of patients' safety and nurses' well-being to be achieved.

Nevertheless, clinical leadership among staff nurses seems important not only for influencing and inspiring peers, but also to achieve an actual change in critical and emergency care and effectively participate in healthcare policy ${ }^{(24)}$. Offering specific leadership programs to frontline nurses may support them to develop a role in transforming both policy and clinical practice. Further research is also needed to explore these issues in different nursing specialties.

The present findings, although significant, need to be viewed under the scope of particular limitations. The main limitation is that only one focus group took place, thus the researchers did not have the opportunity to triangulate the findings with others coming from different groups of participants. Additionaly, the findings of the study were not validated by all participants.

\section{CONCLUSION}

Limited participation in health-related decision-making, lack of education in advanced nursing practice and poor quality of interpersonal relationships among nurses may hinder the enhancement of their professional role. Frontline nurses need to be supported in terms of communication and cooperation with physician and peers, aiming to build strong relationships among them and cultivate their participation in clinical decision-making ${ }^{(1)}$. Moreover, collaboration with physicians and other healthcare professionals, as well as development of alliances with patients and patient carers groups may support nurses to redesign health and social care. Overall, it is proposed nursing education at undergraduate and post-graduate levels to include programs and seminars concerning policy development skills. Further research, including mixed methods studies on the subject, would provide insight on the strategies more likely to affect such changes.

\section{RESUMO}

Objetivo: Investigar preliminarmente a forma como os enfermeiros gregos de enfermagem crítica e de emergência conceituam as mudanças no seu papel profissional. Método: Aplicou-se metodologia qualitativa de grupo focal. Após amostragem intencional e consentimento informado dos participantes. Resultados: Participaram oito indivíduoas. A necessidade de reforçar a participação dos enfermeiros na tomada de decisões para que uma mudança real no seu papel profissional fosse alcançada foi o tema central das narrativas dos participantes. Avanços constatados no desempenho profissional: prática baseada em evidências; tecnologia; educação, conhecimento; habilidades clínicas; pesquisa; profunda colaboração enfermeiro-médico. As razões pelas quais esses avanços não conseguiram reforçar o papel profissional dos enfermeiros foram falta de meritocracia, relações competitivas, falta de apoio entre enfermeiros, apoio hierárquico insuficiente e limitações orçamentárias. Conclusão: Apesar dos avanços na prática clínica, os participantes não consideraram que seu papel profissional foi aumentado significativamente, uma vez que a participação na tomada de decisões e no controle de sua prática permanece limitada. São recomendadas intervenções destinadas a reforçar a participação dos enfermeiros na tomada de decisões clínicas e a aumentar a sua autonomia profissional.

Autonomia Profissional; Tomada de Decisões; Enfermagem em Emergência; Enfermagem de Cuidados Críticos; Papel Profissional. 


\section{RESUMEN}

Objetivo: Investigación preliminar acerca de la manera cómo los enfermeros griegos del departamento crítico y de emergencia conceptualizan los cambios en su papel profesional Método: Una metodología de grupo focal cualitativa fue aplicada. Previo muestreo significativo y consentimiento informado de los participantes. Resultados: Ocho individuos participaron. La necesidad de mejora de la participación de los enfermeros en la toma de decisiones a fin de proporcionar un cambio real en su papel profesional fue el tema central de las narrativas de los participantes. Avances percibidos en el papel estimado de desempeño profesional; prática basada en evidencias; tecnología; educación, conocimiento; habilidades clínicas; investigación; colaboración intensificada enfermero-médico. Razones percibidas por las que dichos avances fallan en mejorar en papel profesional del enfermero fueron la falta de meritocracia; relaciones competitivas; falta de apoyo entre los enfermeros; insuficiente soporte de gestión; limitaciones presupuestarias. Conclusión: Pese a los avances en la práctica clínica, los participantes no consideran que su papel profesional haya mejorado significativamente, puesto que la participación en la toma de decisiones y su control sobre la práctica permanecen limitados. Se recomiendan intervenciones con vistas a incrementar la participación enfermera en la toma de decisiones clínicas e una autonomía profesional general.

\section{DESCRIPTORES}

Autonomía Profesional; Toma de Decisiones; Enfermería de Urgencia; Enfermería de Cuidados Críticos; Rol Profesional.

\section{REFERENCES}

1. Papathanassoglou ED, Karanikola MN, Kalafati M, Giannakopoulou M, Lemonidou C, Albarran JW. Professional autonomy and associations with nurse-physician collaboration and moral distress in European intensive care nurses. Am J Crit Care. 2012;21(2):e41-52. DOI: $10.4037 /$ ajcc201220

2. Bryan-Brown CW. My first 50 years of critical care (1956-2006). Am J Crit Care. 2007;16(1):12-6.

3. Aletras VH, Kallianidou K. Performance obstacles of nurses in intensive care units of Greek National Health System hospitals. Nurs Crit Care. 2016;21(3):157-66. DOI: 10.1111/nicc.12115.

4. Aiken LH, Sloane DM, Bruyneel L, Van den Heede K, Griffiths P, Busse R, et al. Nurse staffing and education and hospital mortality in nine European countries: a retrospective observational study. Lancet. 2014;383(9931):1824-30. DOI: 10.1016/S0140-6736(13)62631-8.

5. Gouzou M, Karanikola M, Lemonidou C, Papathanassoglou E, Giannakopoulou M. Measuring professional satisfaction and nursing workload among nursing staff at a Greek Coronary Care Unit. Rev Esc Enferm USP [Internet]. 2015 [cited 2016 July 04];49;(n. spec):15-21. Available from: http://www.scielo.br/pdf/reeusp/v49nspe/1980-220X-reeusp-49-spe-0015.pdf

6. Greece. Protothema. Extremely high rates of deaths and ICU admissions due to influenza this year [Internet]. 2016 [cited 2016 July 04] Available from: http://www.protothema.gr/greece/article/568009/rekor-thanaton-kai-eisagogon-se-meth-apo-ti-gripi fetos-/ [article in Greek].

7. Kalafati M. How Greek healthcare services are affected by the Euro crisis. Emerg Nurse. 2012;20(3):26-7.

8. Rachiotis G, Kourousis C, Kamilaraki M, Symvoulakis EK, Dounias G, Hadjichristodoulou C. Medical supplies shortages and burnout among Greek health care workers during economic crisis: a pilot study. Int J Med Sci. 2014;11(5):442-7. DOI: 10.7150/ijms.7933

9. Wray J. The impact of the financial crisis on nurses and nursing. J Adv Nurs. 2013;69(3):497-9. DOI: 10.1111/jan.12031.

10. Munhall LP. Provisioning phenomenology: nursing and health science research. New York: National League for Nursing; 1994.

11. Palmer M, Fadden G, Larkin M, Visser R. Developing an interpretative phenomenological approach to focus group data. Qual Res Psychol. 2010;7(2):99-121.

12. Bradbury-Jones C, Sambrook S, Irvine F. The phenomenological focus group: an oxymoron? J Adv Nurs. 2009;65(3):663-71. DOI: 10.1111/j.1365-2648.2008.04922.x.

13. Carey MA. The group effect in focus groups: planning, implementing, and interpreting focus group research: In: Morse JM, editor. Critical issues in qualitative research methods. Thousand Oaks, California: Sage; 1994. p. 225-41.

14. Toren O, Nirel N, Tsur Y, Lipschuetz M, Toker A. Examining professional boundaries between nurses and physicians in neonatal intensive care units. Isr J Health Policy Res. 2011;3(1):43. DOI: 10.1186/2045-4015-3-43.

15. Doherty C. A qualitative study of health service reform on nurses' working lives: learning from the UK National Health Service (NHS). Int J Nurs Stud. 2009;46(8):1134-42. DOI: 10.1016/j.ijnurstu.2009.01.014.

16. Traynor M, Boland M, Buus N. Professional autonomy in 21 st century healthcare: nurses' accounts of clinical decision-making. Soc Sci Med. 2010;71(8):1506-12. DOI: 10.1016/j.socscimed.2010.07.029.

17. Karra V, Papathanassoglou ED, Lemonidou C, Sourtzi P, Giannakopoulou M. Exploration and classification of intensive care nurses' clinical decisions: a Greek perspective. Nurs Crit Care. 2014;19(2):87-97. DOI: 10.1111/nicc.12018

18. Turner C, Keyzer D, Rudge T. Spheres of influence or autonomy? A discourse analysis of the introduction of Nurse Practitioners in rural and remote Australia. J Adv Nurs. 2007;59(1):38-46.

19. Adamou E, Giakoumidakis K, Kadda O, Argyriou G, Kapadochos T, Vasilopoulos G, et al. Exploring nurse's role in Intensive Care Units. Rostrum Asclepius. 2011;10(2):221-38. [article in Greek].

20. France NE. Strengthening clinical nurse specialist role socialization. Clin Nurse Spec. 2005;19(6):294-5.

21. Stoj i Ž, Perkovi L, Staševi I, Stoj i N, Ropac D. Relationship of perception conflict and assertiveness in nurses [abstract]. Acta Med Croatica. 2014;68(3):259-71. [Article in Croatian].

22. Kerzman H, Van Dijk D, Eizenberg L, Khaikin R, Phridman S, Siman-Tov M, et al. Attitudes toward expanding nurses' authority. Isr J Health Policy Res. 2015;4:19. DOI: 10.1186/s13584-015-0005-z. 
23. International Council of Nurses (ICN). 2016-Nurses: a force for change: improving health systems' resilience [Internet]. Geneva: ICN; 2016 [cited 2016 July 03]. Available from: http://www.icn.ch/publications/2016-nurses-a-force-for-change-improving-health-systems-resilience/

24. FyffeT. Nursing shaping and influencing health and social care policy.J Nurs Manag. 2009;17(6):698-706. DOI: 10.1111/j.1365-2834.2008.00946.x.

Financial support

This study has been funded by the Cyprus University of Technology, (internal funding for the project "Prevention and Mental Health Care in the Community"/ research activity. 319). 